\title{
Alcohol-Based Hand Sanitizers: Review of Efficacy and Adverse Effect
}

\author{
Shegun Victor Oluwatuyi ${ }^{1 *}$ (https//orcid.org/0000-0002-7745-0945) \\ Alaba Tolulope Agbele ${ }^{2}$ (https//orcid.org/0000-0002-8756-5754) \\ Modupe Elizabeth Ogunrinde ${ }^{3}$ (http//orcid.org/0000-0002-8248-5632) \\ Awe Tolulope Veronica Ayo $^{2}$ (https//orcid.org/0000-0002-1187-8236) \\ Adelabu Mobolaji $\mathrm{Ayo}^{2}$ (https//orcid.org/0004-0002-5238-4005) \\ Ayoyinka Bridget Fayoke (https//orcid.org/0000-0002-1753-6456) \\ Oluwatuyi Mayowa Funmilayo (https//orcid.org/0000-0001-9709-1639) \\ Ajijola Anuoluwapo Deborah ${ }^{5}$ (https//orcid.org/0000-0002-5676-6246) \\ 1.Department of Public Health, Ekiti State College of Health Sciences and Technology, Ijero Ekiti, Email: \\ diademofglory6797@gmail.com \\ 2.Department of Basic Medical Sciences, Ekiti State College of Health Sciences and Technology, Ijero Ekiti \\ 3.Department of Community Health, Ekiti State College of Health Sciences and Technology, Ijero Ekiti \\ 4.Department of Health Information Management, Ekiti State College of Health Sciences and Technology, Ijero \\ Ekiti \\ 5.Department of Dental Health, Ekiti State College of Health Sciences and Technology, Ijero Ekiti
}

\begin{abstract}
Objective: The use and adverse effect of alcohol-based hand sanitizers as a preventive measure in combating the spread of COVID-19. Materials and Methods: A literature search of the electronic databases including PubMed, Scopus, Research gate and Embase was conducted to retrieve articles investigating the protective effect of alcohol-based sanitizers against the spread of COVID-19 as well as its possible adverse effects. The search timeframe ranged from the inception of each database to August 2020.Results: From an initial search of 456 articles, and after the removal of duplicates as well as applying the predetermined inclusion and exclusion criteria, 74 articles were finally included for this systematic review. Results showed promising protective effect of alcohol-based hand sanitizers against the spread of COVID-19 pandemic. Furthermore, no adverse effect was observed after the use of alcohol-based sanitizers though there are certain possible adverse effect identified which includes skin toxicity, risk of skin burn due flammability etc. Conclusion: Alcohol based hand sanitizers are effective against lipophilic viruses which means they are effective against coronaviruses. To ensure efficacy of the product, the recommended ethanol concentrates should be strictly adhered to and regulated. Alcohol based hand sanitizers has few adverse effects ranging from skin toxicity when ethanol concentrates is relatively high and not regulated courtesy of proliferation of fake products in the market. They are known to be flammable in nature and can cause skin burn if the safety and precautionary instructions are not strictly adhered to. Hand hygiene and the use of alcohol based hand sanitizers are effective in preventing direct and indirect spread of COVID-19.
\end{abstract}

Keywords: Alcohol-Based Hand Sanitizer; Pandemic; COVID-19; Disinfectants; Disease Prevention

DOI: $10.7176 / \mathrm{JHMN} / 81-01$

Publication date:October $31^{\text {st }} 2020$

\section{Introduction}

Many Countries including Nigeria focuses on regular hand washing practice and use of alcohol-based hand sanitizer as a means of preventing coronavirus spread ${ }^{[1]}$. This article focused on the use of alcohol based hand sanitizers and its effectiveness in the prevention of COVID-19 while also considering its adverse effects. COVID-19 (Coronavirus Disease-2019) pandemic is of great concern to public health.

The use of alcohol based hand sanitizer is globally practiced in an effort to prevent rapid spread of the virus ${ }^{[2]}$. The total number of coronavirus cases in the world has risen to over twenty-three million (23Million) ${ }^{[3]}$. Due to the contagious nature of the virus, the use of disinfectants such as alcohol based hand sanitizer becomes apparent. COVID-19 or n-COV 2019 is a contagious disease caused by the severe acute respiratory syndrome coronavirus 2 (SARS-CoV-2), which can persist and remain infectious on surfaces for up to 9-14days ${ }^{[1,2,3]}$.

Studies have shown that the spread is rapid in confine space and crowd with the presence of an infected host. The agent is dispersed in the air when an infected person sneezes or coughs. The virus is enveloped in the droplets for hours and can survive on surfaces for 24-48hours ${ }^{[4]}$. The need to break the route of transmission becomes more apparent through early detection, contact tracing, isolation, use of nose mask or face shield, regular hand-washing practice and use of alcohol based hand sanitizer has been made primus-inter-pares among other measures put in place to prevent COVID-19 spread. Nigeria Centre for Disease Control (NCDC) encourages Nigerian citizens through daily text on the tips of preventing the virus spread. 
The use of alcohol based hand sanitizer was tipped as effective hand disinfectants against the spread of the virus. Due to this development; the demand for alcohol based hand sanitizers skyrocketed in commercial stores. Health institutions such as Ekiti State college of Health sciences and Technology Ijero Nigeria produced mini sanitizers courtesy of the Community Health department; there are also different brands of hand sanitizer proliferated in the market. Some of these sanitizers despite the hike prices are ineffective as they are not alcohol based. The World Health Organization (WHO) recommends alcohol-based hand sanitizer (ABHS) in line with the proven advantages of their rapid action and a broad spectrum of microbicidal activity to ensure protection against bacteria and viruses. However, the effectiveness against non-enveloped viruses is still debatable and questionable. ${ }^{[5.6 .7 .8]}$

Hand sanitizers types

Figure 1: different types of hand sanitizers

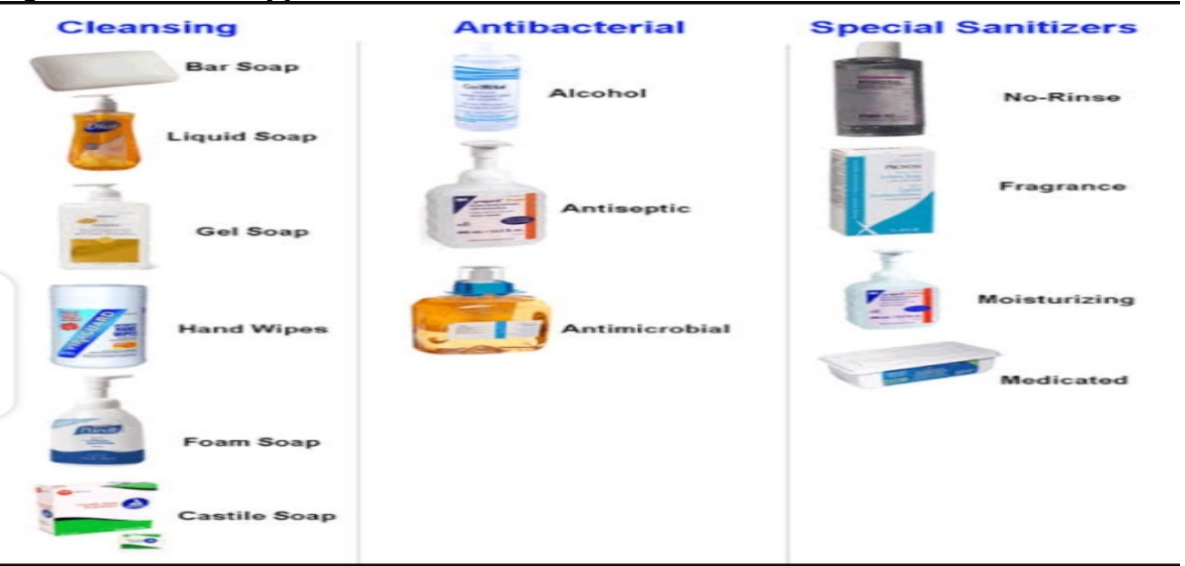

Based on the figure above we have three categories of sanitizers namely:

1. Cleansing Bar soap, Liquid soap, Gel soap, Hand wipes, Foam soap, castile soap

2. Antibacterial: Alcohol, Antiseptic, Antimicrobial

3. Special sanitizers: No-rinse, Fragrance, Moisturizing, medicated

Presently, according to World Health Organization, alcohol based hand sanitizers are the most effective formulations due to its capability to denaturalize proteins of microbes and making virus inactive ${ }^{[9,10] \text {. Though }}$ alcohol based hand sanitizers are slightly flammable and could lead to skin toxicity when alcohol content is too high ${ }^{[11,12]}$. This systematic review will look into alcohol based hand sanitizers, their effectiveness and possible adverse effect.

\section{Materials and methods Search strategy}

The reporting of this systematic review was done in line with the statement of preferred reporting items for systematic reviews and meta-analyses (PRISMA) Moher, D., et al., Preferred reporting items for systematic reviews and meta-analyses: the PRISMA statement. 2009. 6(7): p. e1000097. An electronic literature search was conducted in August 2020 using the following databases; PubMed, Scopus, and Embase for articles published in English language investigating the efficacy of alcohol-based hand sanitizers, without restriction on year of publication. The search keywords were as follows: "alcohol-based hand sanitizers" and "COVID-19". Manual screening of references of retrieved studies was conducted to also obtain relevant studies.

\section{Inclusion criteria}

The retrieved articles were included based on the following criteria:

- Studies that were conducted to determine the effectiveness of alcohol-based hand sanitizers which were published in English language;

- Studies that used alcohol-based hand sanitizers;

- Experimental and clinical studies with full texts.

\section{Exclusion criteria}

Studies were excluded based on the following criteria:

- Studies in which alcohol-based hand sanitizer was not used;

- Studies in which alcohol was used in combination with other agents;

- Studies that made use of other forms of reagents;

- Studies that evaluated the effectiveness of alcohol-based hand sanitizers with other reagents; and 
- Conference abstracts, case reports, letters, review articles, editorials,

- Unpublished data, articles without full texts, and non-English articles.

\section{Study selection}

All articles retrieved from the electronic databases as well as manual searches were entered into endnote software (EndNote version X9, New York, NY, USA) for removal of duplicates. Thereafter, two authors (V.S.O. and A.T.A.) independently reviewed the titles and abstracts of the retrieved studies for eligibility. Studies were then selected based on the predetermined inclusion and exclusion criteria. For any disagreements concerning the inclusion of studies, all authors agreed on a consensus based on factual evidence.

\section{Data extraction}

The data from each eligible study were extracted and checked by the authors. The following information were carefully obtained from each included study: first author name, subject, frequency of use as well as findings. Furthermore, these data were summarized and presented in a tabular form.

\section{Results}

\section{Literature search}

The PRISMA flow diagram of our search results is shown in figure 1. Initial search gave a total of 456 articles, with the breakdown as follows: 430 articles were from the three electronic databases (PubMed, Scopus and Embase) and 26 articles obtained through a manual search. From these figures, 186 articles were retained after the removal of duplicates. Thereafter, following careful examination and screening of their titles and abstracts as well as the application of the inclusion and exclusion criteria, a further 98 records were excluded. The full texts of the remaining 88 records were assessed. We excluded 10 articles for non-English language publication, while 4 more articles were removed for not having full texts. Finally, a total of 74 studies were included in this systematic review.

\section{Study characteristics}

The summary of included studies and characteristics is presented in table 1. These articles were published between November 2019 and August 2020, employed an experimental design.

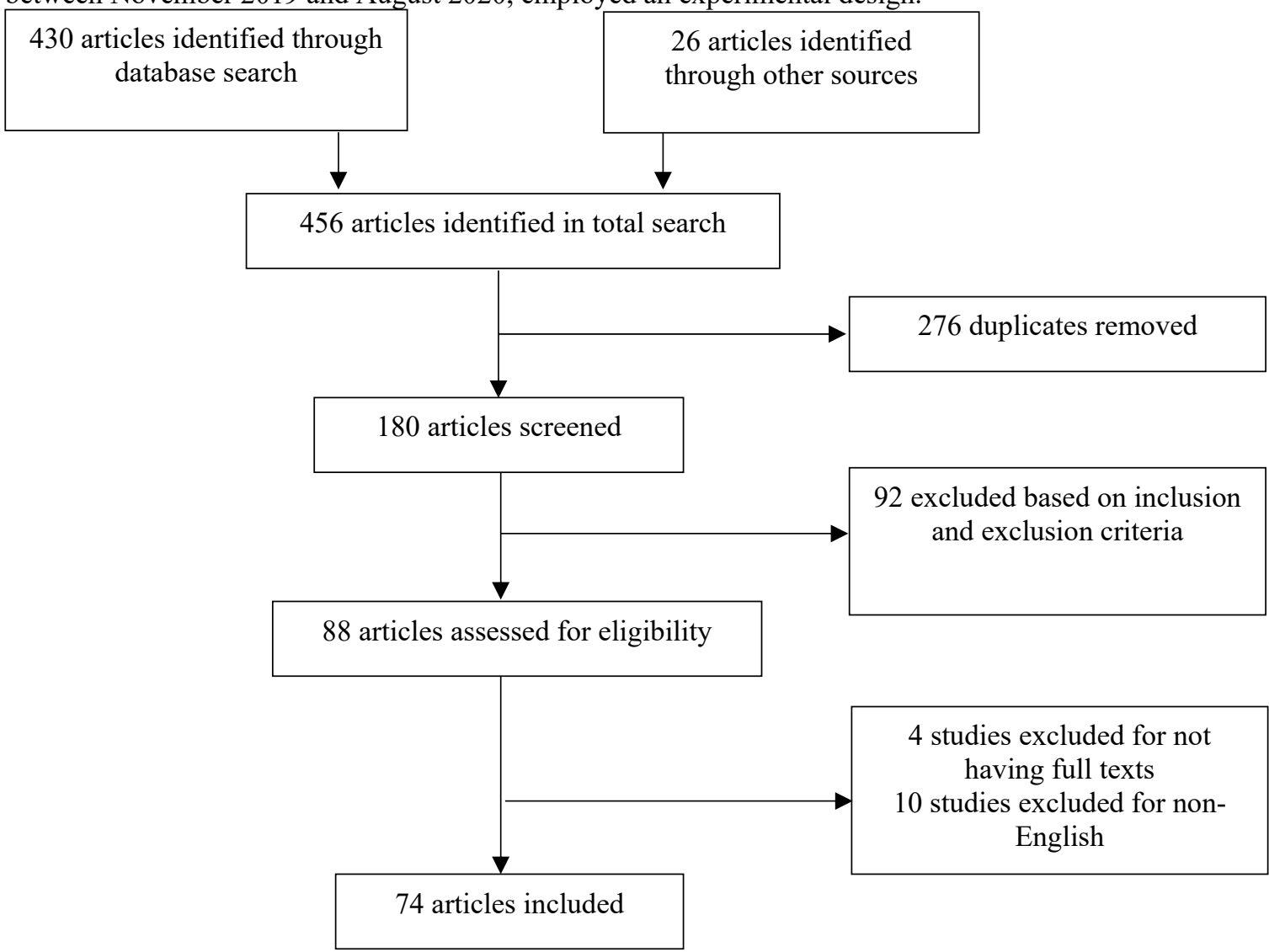

Figure 1. Preferred reporting items for systematic reviews and meta-analyses (PRISMA) flow diagram for the selection of included Articles 


\section{Hand Sanitizers}

Hand sanitizers are hand based disinfectants and they are majorly classified into two namely: Alcohol- Based and Alcohol-Free hand sanitizers ${ }^{[15]}$. Alcohol based hand sanitizers has alcohol contents and they are effective against microbes of all kinds. Their mode of action can be to destroy, inhibit or inactivate micro-organisms ${ }^{[16,17]}$. They are exquisitely effective in the prevention of COVID-19 if its use is strictly adhered to.

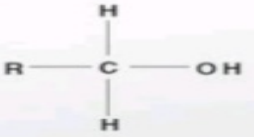

Primary Alcohol

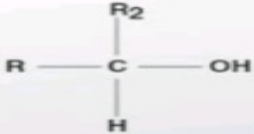

Secondary Alcohol

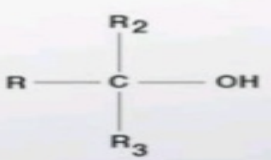

Tertiary Alcohol

Alcohol based hand sanitizers removes bacteria, virus, fungi etc. without the need for wet additions as it dries off instantly due to alcohol contents. Alcohol free sanitizers are the types that have no alcohol content and they include antiseptics soaps, gels, moistures etc. they have varied usage and mode of action ${ }^{[18,19]}$. They are most safe to use and apply. This review showed that the most widely used and affordable alcohol free sanitizers are antiseptic soaps and liquid soaps ${ }^{[20,21,22]}$. The National Agency for Drug Administration and Control (NAFDAC) has a detailed list of antiseptics that are approved for use against broad spectrum of microbes. This will serve as a guide for consumers to choose the right product as applicable to their mode of action and intended use. It is also noteworthy that there are certain antiseptics that are effective than some sanitizers ${ }^{[23]}$. Hospitals and health care workers prefer the use of antiseptic and hand washing practice but the practice is often flawed ${ }^{[24]}$ The practice becomes easier when alcohol based hand sanitizers are used as it does not waste time.

Different constituents Alcohol based hand sanitizers

\section{- Ethanol}

Ethanol is a chemical compound, a simple alcohol with the chemical formula $\mathrm{C}_{2} \mathrm{H}{ }_{6} \mathrm{O}$. Its formula can be also written as $\mathrm{CH}_{3}-\mathrm{CH}{ }_{2}-\mathrm{OH}$ or $\mathrm{C}_{2} \mathrm{H}{ }_{5} \mathrm{OH}$, and is often abbreviated as EtOH. Ethanol is a volatile, flammable, colorless liquid with a slight characteristic odor.[25]

\section{Formula: C2H5OH}

Ethanol is an important industrial chemical; it is used as a solvent, in the synthesis of other organic chemicals, and as an additive to automotive gasoline (forming a mixture known as a gasohol). Ethanol is also the intoxicating ingredient of many alcoholic beverages such as beer, wine, and distilled spirits.<smiles>CCO</smiles>

\section{- Isopropanol}

Isopropyl alcohol is a colorless, flammable chemical compound with a strong odor. As an isopropyl group linked to a hydroxyl group, it is the simplest example of a secondary alcohol, where the alcohol carbon atom is attached to two other carbon atoms. It is a structural isomer of 1-propanol and ethyl methyl ether. Wikipedia

\section{Formula: C3H8O}

Isopropanol is used in soaps and lotions as an antiseptic. Isopropyl alcohol or 2-propanol is an isomer of 1propanol. It is a colorless liquid having disinfectant properties. It is used in the manufacture of acetone and its derivatives and as a solvent [26,27]<smiles>CC(C)O</smiles> 


\section{- Propanol}

Propanol is a primary alcohol with formula $\mathrm{CH} 3 \mathrm{CH} 2 \mathrm{OH}$. This colorless liquid is also known as propan-1ol, 1-propyl alcohol, n-propyl alcohol and n-propanol. It is an isomer of 2-propanol [28]

\section{Formular: $\mathrm{C}_{3} \mathrm{H}_{8} \mathrm{O}$}<smiles>CCO</smiles>

About $65 \%-90 \%$ of alcohol concentrates in a given hand sanitizer is effective to destroy or act against microbes as the lipid membrane of microbes are altered ${ }^{[29]}$. Alcohols have broad-spectrum antimicrobial activity against bacteria, viruses, fungi etc. though they can be less effective when it comes to protozoa ${ }^{[30]}$

\section{Effectiveness}

Alcohol based hand sanitizers are available in market stores, pharmacy store and they can be kept on our desk, bags, vehicles and can also be available in different facilities we frequent. Alcohol based hand sanitizers are effective in destruction of viruses, bacteria and other pathogens. But it leaves questions such as; which hand sanitizer is the most effective? Is hand sanitizer better than Alcohol based hand sanitizer? Basically, there are two major products namely; Alcohol-based gels and Alcohol-free foaming hand sanitizers. They both have benefits and drawbacks. Alcohol based hand sanitizers are rubbed on the palm and they are thereafter absorbed by the skin. The skin made up of three layers namely; superficial epidermis, dermis and hypodermis. The skin no doubt has its own defence mechanism as it protects against invasion of microbial agents ${ }^{[31]}$. Studies have shown that long term usage antibiotics, hand sanitizers and hand washing disrupt distribution of skin flora ${ }^{[32]}$. The even distribution and micro-biota balance is important to reduce virulence ${ }^{[33]}$. Naturally there is skin regeneration which takes about twenty-eight days starting from the mitotic division of basal epithelium to desquamation ${ }^{[34]}$. When the dead keratinocytes in the skin are removed, it takes away the microbes that colonized the skin surface. This continuous process significantly limits the invasion of bacteria while achieving a balanced growth among the microbial populations ${ }^{[35,36]}$. The Coronavirus has a unique genome sequence that is similar to Severe Acute Respiratory Syndrome as they share almost same morphology since they belong to the same genus Beta Coronavirus ${ }^{[37]}$. They are positive single stranded RNA viruses. The good news is that, these viruses can be removed, deactivated or rendered redundant by solvent (Lipid in nature) such as propanol, isopropanol and ethanol. Their growth can also be inhibited by certain disinfectants, chloroform and antiseptics [38,39]. Concentrates of about $60 \%-80 \%$, is a potent agent effective against lipophilic viruses and hydrophilic viruses ${ }^{[40]}$. The recommended level of ethanol in hand sanitizers according to World Health Organization is $80 \%$, for isopropanol $75 \%$ while Propanol is $70 \%$. However, studies have shown that $60 \%-80 \%$ of ethanol is effective against viruses while the same cannot be said about propanol and isopropanol on the same scale respectively ${ }^{[41,42]}$. A study conducted with WHO showed a demonstration of the effectiveness of alcohol as a strong viricidal against emerging pathogens such as Ebola Virus, Zika Virus, SARS-CoV, and MERS-CoV ${ }^{[43]}$. Another study conducted in Germany found that the ethanol in the concentration of $42.6 \%$ was able to destroy SARS coronavirus and MERS coronavirus hence we can conclude that the effectiveness of alcohol based hand sanitizers varies based on concentration levels ${ }^{[44]}$. Detergents has the ability to wash off microbes while alcohol based hand sanitizers has the ability to destroy micro-organisms; any agents that is not killed in the process by the use of alcohol based hand sanitizers can be washed away using soap and water. They have similar properties though different molecules. The FDA recommends that hand sanitizers should contain $60 \%-95 \%$ alcohol for maximum protection against germs. Albeit, Alcohol based hand sanitizers are recommended by leading health organizations (National \& International) such as NCDC, WHO and FDA, NAFDAC etc. Alcohol based hand sanitizers are by far the most widely used sanitizers in Hospitals and other health care facilities. Its effectiveness has been proven time and time again, withstanding the test of time.

\section{Adverse Effect}

There is little adverse effect of alcohol based hand sanitizers and they are identified as follows;

- Temporal effect on Microbes

- Weak action against Some microbes (Non-lipophilic virus, bacterial spores and protozoa

- Flammability

- Skin Toxicity

- Antibiotic resistance

- Alcohol poisoning

- Hormonal disruption

- Weaker immune system 
- Using Alcohol-based hand sanitizer every day can disrupt your microbiome

- Adverse impact on skin and promotes ageing

- We could be creating a stronger agent

- If you have cuts on your hands, using hand sanitizer every day will hurt

- Dry Hands

- Irritation

- If you handle chemicals, using hand sanitizer every day can be dangerous

- You can still get sick if you use hand sanitizer every day

- Impaired muscles

Alcohol based hand sanitizers are known to be highly flammable due to alcohol concentrates and as such can be dangerous when carelessly used near fire source ${ }^{[45]}$. There were reported cases of skin burn sustained due to use of alcohol based hand sanitizers. The victims were said to have handled cooking immediately after applying Alcohol based hand sanitizer while the moist was still very much on the skin surface. It is advisable to stay away from fire source after application of Alcohol based hand sanitizers at least until the skin surface is dry. Alcohol based hand sanitizers are not effective against non-lipophilic virus, bacteria spores and protozoa hence those who do not have this knowledge would assume they are safe when dealing with virus that are nonlipophilic after using alcohol based hand sanitizers ${ }^{[46]}$. It should be noted that alcohol based hand sanitizers is effective against Coronaviruses as they are lipophilic viruses. There can also be case of skin toxicity due to high concentration of alcohol above the recommended limit ${ }^{[47]}$. Since there are various brands of alcohol based hand sanitizers proliferated in markets without regulation, there are risk of sale and use of products that could cause skin toxicity due to potent level of alcohol. It is advisable to select products with less irritating agents and moisturizing skin after hand hygiene and avoiding habits that may cause or aggravate skin irritation. Health workers can also use products that are effective, safe and compatible with all skin types ${ }^{[48]}$. To reduce or forestall the problems listed above alcohol based hand sanitizers containing humectants or emollients can be utilised [49]. There are researches and studies on the use of Benzethonium Chloride which broadens the effectiveness against viruses and at the same addresses the adverse effect on skin as it tackles concerns about flammability associated with alcohol based hand sanitizers ${ }^{[50]}$. However, it should be noted that standard hand washing practice is preferable and more effective if the hands are visibly dirty, greasy or contaminated as the hand surface coverage when alcohol based hand sanitizers are used stands at 20-30seconds hence the coverage is limited ${ }^{[50,51]}$. Alcohol based hand sanitizers contains ethanol and isopropanol and they are both effective in killing germs and viruses however high concentration of ethanol in alcohol based hand sanitizers is of major concern in Nigeria. The installation of alcohol based dispensers in hospitals and health centres has to resort to consulting with local fire-fighting services due to their level of flammability. More worrisome is the potential toxicity when ingested accidentally or incidentally. Since they can be easily opened, it should be kept out of the reach of children as its high level of consumption can lead to acute alcohol poisoning. Another possible side effect of prolonged use of alcohol based hand sanitizers is the dryness and cracking of skin (Palm). Alcohol has the ability to remove oil on skin surfaces and reduces its ability to retain moist hence the temporary loss of these moist and oils can lead to symptoms of dermatitis. Alcohol based hand sanitizers can also stain areas where sanitizer dispensers may leak or drip.

In the face of the covid-19 scourge, the use of hand sanitizers is seen as alternative to hand washing. Triclosan, a common active ingredient found in hand sanitizers known to be effective in killing microbes found on hands, may also lead to the development of antibiotic-resistant bacteria. A 2018 study published in the journal Environment International found this out. There are other side effects of hand sanitizers too, that you need to be aware of which includes:

\section{Alcohol poisoning}

The presence of alcohol concentrates in hand sanitizers is to ensure hand hygiene and just because it's for hygiene, doesn't mean it's completely safe. Most of the hand sanitizers have alcohol as an active ingredient which kills bacteria. Though, the quantities of the alcohol present in a sanitizer are fixed, it can still cause poisoning. Experts believe that a few squirts of a hand sanitizer are equal to a couple of alcohol shots. Now this can be dangerous, especially for kids. While it can be an alternative, it should be used in a limited amount.

\section{Antibiotic resistance}

Antibiotics are helpful against the growth of bacteria in body. But we need to ask the question; what if our body develops a resistance against it? Or in turn develops bacteria that's resistant to antibiotics? Yes, that could be a possible threat of using hand sanitizers. The active ingredient Triclosan present in hand sanitizers is responsible for the development of antibiotic resisting bacteria. So, in a way, using hand sanitizers to keep diseases away may impact otherwise. It can kill good bacteria that help in fighting diseases. This means lower resistance 
towards diseases and infections.

\section{Hormonal disruption}

Triclosan has other side-effect-it's responsible for hormonal disruption in body. A few studies say that this compound cause bacteria to adapt to its antimicrobial conditions. This further causes antibiotic-resistant strain leading to hormonal fluctuations in body. This has raised serious concerns among health professional regarding the use of hand sanitizers. They believe that any disruption to the natural environment inside the body has detrimental health effects. This hormonal imbalance can lead to infections and diseases.

\section{Weaker immune system}

Our immune system work on a different programming - it's auto-tuned to fight diseases. It reacts actively against diseases when disease causing bacteria or viruses attack the body. In a situation of extreme clean environment, immune system in a way find no harmful entity to work against. And therefore, it results in its weaker performance. Studies has shown if a human is exposed to such clean conditions early on life, it contributes to weaker defense by immune system at the later stage. Researchers at University of Michigan School of Public Health found that triclosan can negatively impact immune system functioning. The study showed that higher levels of triclosan in children and teens led to hay fever and allergy susceptibility in them.

\section{Adverse impact on skin and promotes ageing}

The alcohols most commonly found in hand sanitizers are isopropyl, ethanol, and n-propanol. These alcohols are also responsible for drying out the skin. They strip away the natural oils of the skin and also cause irritation. The acid present in hand sanitizers dehydrate skin cells and may also lead to contact dermatitis. In a long run, it can also damage skin cells.

Use of hand sanitizers may also lead to ageing of the hand's skin. Dry skin and dehydration can cause callous formation, flaky skin, wrinkles and cracks. Increased dehydration can also kill the natural barrier of the skin against infections. This means reduced ability of skin to protect itself leading to increase in dehydration and dry skin.

\section{Using Alcohol-based hand sanitizer every day can disrupt your microbiome}

One thing hand sanitizer is especially good at is killing microbes, which is how it keeps people safe from a wide variety of illnesses. However, sanitizer is actually a little too good at killing bacteria, according to microbiologist Jonathan Eisen. "One aspect of hand sanitizers that is usually overlooked is that they can affect bodies' microbiomes in a few ways, and some of these ways could be bad," he revealed in an interview with Popular Science.

That's because it kills off bacteria that's beneficial for keeping our bodily functions in order.

Because hand sanitizer can wreak havoc on our healthy bacterial communities, Eisen advises against using it every day.

\section{We could be creating a stronger agent}

Hand sanitizer can be a culprit in potentially dangerous conditions. So, if you're using it liberally every day, that can become problematic, as noted by board-certified internal medicine physician Seema Sarin. "According to the $\mathrm{CDC}$, hand sanitizer with antibacterial ingredients may also contribute to the development of antibiotic-resistant bacteria. What's so scary about antibiotic-resistant bacteria anyway? According to the CDC, these pathogens have developed the ability to tolerate the drugs that otherwise should be able to kill them. That means if you catch one of these bugs, your normal course of antibiotic medication won't be effective at clearing them from your body. You can still get sick if you use hand sanitizer every day

\section{You can still get sick if you use hand sanitizer every day}

The CDC asserts that hand sanitizer does effectively kill germs and is a good alternative to soap and water when one is unable to wash their hands. Still, hand sanitizer isn't a magical elixir — regardless of what the bottle claims. As registered nurse Kristina Duda pointed out, you can't always trust the claims of hand sanitizer makers. "The U.S. Food and Drug Administration (FDA) has taken legal action against some hand sanitizer companies for making unproven claims against salmonella, e. Coli, Ebola, rotavirus, influenza, and MRSA," Duda revealed in an article for Verywell Health.

That doesn't mean hand sanitizer is ineffective, though, as Duda noted that some science is on the side of hand sanitizer manufacturers. "At the same time, though, studies are beginning to suggest that alcohol-based hand sanitizers may be effective at killing some of these germs," she continued. Duda added, however, that some manufacturers remain in need of FDA approval, so any claims they make can't be trusted. And, as is often the case, more research is needed. 


\section{If you handle chemicals, using hand sanitizer every day can be dangerous}

If you work with chemicals all day, every day, you definitely want to make sure your hands are clean at the end of your shift. Such would be the case for cleaning service workers, farm workers who handle various forms of pesticides, auto technicians, and any other profession wherein you have to work with ultra-strong cleaning and de-greasing agents. You definitely don't want to go home with those all over your hands

However, hand sanitizer is the last thing you want to reach for to clean your paws every day, as the combination of the liquid gel and chemicals can be all kinds of bad for your health. According to a study published in the Journal of Occupational and Environmental Medicine, farm workers who used hand sanitizer actually had increased levels of pesticides in their bodies as opposed to those who didn't use the sanitizer. That's one reason why the CDC cautions against the practice and instead advises you simply wash your hands with soap and water. Gloves may be your friend as well, in some situations, though they are not a substitute for handwashing.

\section{Dry hands}

Using hand sanitizer every day causes hands to become incredibly dry? There's a reason for that, as noted by Janette Nesheiwat, a family and emergency medicine doctor. "Hand sanitizers contain alcohol, which will dry out your skin, but that can be fixed with moisturizer and staying hydrated.

It's also worth noting that dry skin can be more than just annoying. If your hands are dry to the point they become cracked, you may be more susceptible to infection. "It at least seems plausible," microbiologist David Coil told Reader's Digest. So if you absolutely have to use hand sanitizer, try to limit it to one time after your hands become contaminated instead of repeatedly

\section{Irritation}

Using hand sanitizer every day can cause some unpleasant skin irritation, according to surgical oncologist Trevan Fischer. "Repeated use of anything, including hand sanitizer, can cause chronic irritation, skin breakdown, and damage," he explained to MSN. That would make it pretty tough to get things done, especially if you work extensively with your hands.

This is especially the case if you opt for specific kinds of hand sanitizer, as noted by Fischer. "If you're using very high concentrations of alcohol, it can cause ... cracks in the skin," he continued. "Not only does it not feel good when the alcohol hits the skin, but then the skin won't heal as well." Sounds like that could be a problem for a while!

If you want to avoid the adverse skin issues, you can select an alcohol-free hand sanitizer instead, but know that it will be far less effective than alcohol-based formulas. In fact, the CDC only recommends using hand sanitizer that contains at least 60 percent alcohol.

\section{If you have cuts on your hands, using hand sanitizer every day will hurt}

Are you someone who reaches for an alcohol swab immediately after cutting yourself? As it turns out, that's an antiquated practice, according to wound care expert Dr. Kazu Suzuki. "In the wound care world, we say, 'don't put anything in your wound that you wouldn't put in your eye,"' he shared with the Los Angeles Times. "Yes, it will kill some bacteria, but it also kills and irritates healthy skin and the wound bed." It's also going to pack quite the sting!

That's also the mechanism at work when you use alcohol-based hand sanitizer on a cut — which if you've ever accidentally done, you know it can hurt quite a bit. Specifically, alcohol on a wound stimulates the vanilloid receptor-1, or VR1, in your body, as noted by analytical chemist Joseph Glajch. "So, all of a sudden, you feel like you're getting burned, even though you're not getting burned," he said in an interview with Live Science.

\section{Impaired muscles}

While some of the negative side effects of using hand sanitizer every day are relatively minor, some of them can be significantly more concerning. One alarming impact hand sanitizer can potentially have on our body is impairing our muscles - that is, if it contains triclosan, which many sanitizers do.

According to an article in The Atlantic, researchers at the University of Colorado and the University of California, Davis found that triclosan prevented muscular contraction just 10 to 20 minutes after exposure. It also reduced both grip strength and heart function in mice, and impaired the swimming ability of fathead minnow larvae.

While the implications of the study don't pose much of a threat to healthy people, those with heart failure could experience dangerous muscle impairment due to triclosan. Wild animals may also be vulnerable, which isn't good news for their survival rates if exposed. 


\section{Conclusion}

Alcohol based hand sanitizers are effective against lipophilic viruses which means they are effective against coronaviruses ${ }^{[52,53,54]}$. To ensure efficacy of the product, the recommended ethanol concentrates should be strictly adhered to and regulated ${ }^{[56,57]}$. Alcohol based hand sanitizers has few adverse effects ranging from skin toxicity when ethanol concentrates is relatively high and not regulated courtesy of proliferation of fake products in the market ${ }^{[59,60,61]}$. They are known to be flammable in nature and can cause skin burn if they safety and precautionary instructions are not strictly adhered to. Hand hygiene and the use of alcohol based hand sanitizers is effective in preventing direct and indirect spread of COVID-19 ${ }^{[63,64,65]}$. The number of $n-C O V$ virus is removed on contaminated hand surface. Hand hygiene should be routinely done by health care workers before and after handling of devices, health care instruments and medical appliances; before and after contact with patients; exposure to bodily fluids or secretions of patients; before and after any health care services ${ }^{[66,67,68,69,70]}$. While individuals should practice hand hygiene after getting home from a public transport; after return from the market; after contact with surfaces; after handling of appliances and instruments in the church, mosques, schools etc. Hand washing with preparations containing anti-microbial agents can mechanically remove the microbial agents ${ }^{[71,72,73,74]}$. The Nigeria Centre for Disease and Control recommended hand washing with soap and water as it reduces the amount of germs and chemicals on hand surfaces but in cases where water and soap is not available, alcohol based hand sanitizers with concentration of minimum of $60 \%$ and maximum of $80 \%$ ethanol is effective in preventing COVID-19.

\section{Recommendations}

- Recommendations were made to the public on the safe use of alcohol based hand sanitizers while the Government and Health institutions were encouraged to produce standard/low cost hand sanitizers in the fight against this pandemic.

- Appropriate hand washing habit using soap and water is also effective in situations where Alcohol based hand sanitizer is not affordable or accessible.

- Selection of standard Alcohol based hand sanitizers with recommended concentrate of ethanol.

- Hand-washing practice with soap and water as a practice and advisable that we simply wash our hands with soap and water. Gloves may be our friend as well, in some situations, though they are not a substitute for hand-washing.

Conflict of Interest: The authors have no conflicts of interest to declare.

Financial Disclosure: The authors declared that this study has received no financial support.

\section{References}

1. Abiodun D.;Oluwatuyi V.;Fasoro O.;Olusuyi A.;Odeyemi T.;Adewumi M.;Ogunyemi K. A Potential Review into the Clinical Characteristics of 2019-Ncov and its Potential Impact on African Economy. 2020. International Journal of Public Health and Safety. Volume5,DOI10:37241/ijphs.2020.5.189.

2. COVID-19 Coronavirus 2019-nCov Statistics Update (Live): 4,122,912 Cases and 280,337 Deaths. Available online: https://virusncov.com/ (accessed on 8May 2020). Situation Update Worldwide, as of 7 May 2020. Available online: https://www.ecdc.europa.eu/en/ geographical-distribution-2019-ncov-cases (accessed on 7 May 2020).

3. Kampf, G.; Todt, D.; Pfaender, S.; Steinmann, E. Persistence of coronaviruses on inanimate surfaces and their inactivation with biocidal agents. J. Hosp. Infect. 2020, 104, 246-251. [CrossRef] [PubMed]

4. Chan, J.F.W.; Yuan, S.; Kok, K.H.; To, K.K.W.; Chu, H.; Yang, J.; Xing, F.; Liu, J.; Yip, C.C.Y.; Poon, R.W.S.; et al. A familial cluster of pneumonia associated with the 2019 novel coronavirus indicating personto-person transmission: A study of a family cluster. Lancet 2020, 395, 514-523. [CrossRef]

5. Van Doremalen, N.; Bushmaker, T.; Morris, D.H.; Holbrook, M.G.; Gamble, A.; Williamson, B.N.; Tamin, A.; Harcourt, J.L.; Thornburg, N.J.; Gerber, S.I.; et al. Aerosol and Surface Stability of SARS-CoV-2 as Compared with SARS-CoV-1. N. Engl. J. Med. 2020, 382, 1564-1567. [CrossRef] [PubMed]

6. Thomas, Y.; Boquete-Suter, P.; Koch, D.; Pittet, D.; Kaiser, L. Survival of influenza virus on human fingers. Clin. Microbiol. Infect. 2014, 20, O58-O64. [CrossRef] [PubMed]

7. Seto, W.H.; Tsang, D.; Yung, R.W.H.; Ching, T.Y.; Ng, T.K.; Ho, M.; Ho, L.M.; Peiris, J.S.M. Advisors of Expert SARS group of Hospital Authority E_ectiveness of precautions against droplets and contact in prevention of nosocomial transmission of severe acute respiratory syndrome (SARS). Lancet 2003, 361, 1519-1520. [CrossRef]

8. Kampf, G.; Kramer, A. Epidemiologic background of hand hygiene and evaluation of the most important agents for scrubs and rubs. Clin. Microbiol. Rev. 2004, 17, 863-893. [CrossRef]

9. Oluwatuyi VS.; Okunade RA; Oluwatuyi MF.; Agbele AT.; Sam-Ijadele OI.; Mojisola B. COVID-19 in Ekiti State, Nigeria; Why Should we worry? 2020, International Journal of Research and scientific 
Innovation, Volume 7, Issue VI, 146-149

10. Hulkower, R.L.; Casanova, L.M.; Rutala, W.A.; Weber, D.J.; Sobsey, M.D. Inactivation of surrogate coronaviruses on hard surfaces by health care germicides. Am. J. Infect. Control 2011, 39, 401-407. [CrossRef]

11. Yu, I.T.; Xie, Z.H.; Tsoi, K.K.; Chiu, Y.L.; Lok, S.W.; Tang, X.P.; Hui, D.S.; Lee, N.; Li, Y.M.; Huang, Z.T.; et al. Why Did Outbreaks of Severe Acute Respiratory Syndrome Occur in Some Hospital Wards but Not in Others? Clin. Infect. Dis. 2007, 44, 1017-1025. [CrossRef]

12. Centers for Disease Control and Prevention. Prevention of Coronavirus Disease 2019 (COVID-19). Available online: https://www.cdc.gov/coronavirus/2019-ncov/prepare/prevention.html (accessed on 8 May 2020).

13. Manocha, S.;Walley, K.R.; Russell, J.A. Severe acute respiratory distress syndrome (SARS): A critical care perspective. Crit. Care Med. 2003, 31, 2684-2692. [CrossRef]

14. Fendler, E.; Groziak, P. E cacy of Alcohol-Based Hand Sanitizers Against Fungi and Viruses. Infect. Control Hosp. Epidemiol. 2002, 23, 61-62. [CrossRef] Int. J. Environ. Res. Public Health 2020, 17, 332614 of 17

15. Gerberding, J.L.; Fleming, M.W.; Snider, D.E., Jr.; Thacker, S.B.; Ward, J.W.; Hewitt, S.M.; Wilson, R.J.; Heilman, M.A.; Doan, Q.M. Morbidity and Mortality Weekly Report Guideline for Hand Hygiene in Health-Care Settings; Recommendations of the Healthcare Infection Control Practices Advisory Committee and the HICPAC/SHEA/APIC/IDSA Hand Hygiene Task Force; Centers for Disease Control: Atlanta, GA, USA, 2002; Volume 51. 16.

16. Sattar, S.A. Microbicides and the environmental control of nosocomial viral infections. J. Hosp. Infect. 2004, 56, 64-69. [CrossRef] [PubMed]

17. Dixit, A.; Pandey, P.; Mahajan, R.; Dhasmana, D.C. Alcohol based hand sanitizers: Assurance and apprehensions revisited. Res. J. Pharm. Biol. Chem. Sci. 2014, 5, 558-563.

18. Kramer, A.; Galabov, A.S.; Sattar, S.A.; Döhner, L.; Pivert, A.; Payan, C.;Wol , M.H.; Yilmaz, A.; Steinmann, J. Virucidal activity of a new hand disinfectant with reduced ethanol content: Comparison with other alcohol-based formulations. J. Hosp. Infect. 2006, 62, 98-106. [CrossRef]

19. Erasmus,V.; Daha, T.J.; Brug, H.; Richardus, J.H.; Behrendt, M.D.; Vos, M.C.; van Beeck, E.F. Systematic Review of Studies on Compliance with Hand Hygiene Guidelines in Hospital Care. Infect. Control Hosp. Epidemiol. 2010, 31, 283-294. [CrossRef]

20. Moher, D.; Liberati, A.; Tetzla_, J.; Altman, D.G. Preferred Reporting Items for Systematic Reviews and Meta-Analyses: The PRISMA Statement. PLoS Med. 2009, 6, e1000097. [CrossRef]

21. Gold, N.A.; Avva, U. Alcohol Sanitizer; StatPearls Publishing: St. Petersburg, FL, USA, 2018.

22. Van Asselt, A.J.; Te Gi el, M.C. Pathogen resistance and adaptation to disinfectants and sanitisers. In Understanding Pathogen Behaviour; Elsevier Ltd.: Amsterdam, The Netherlands, 2005; pp. 484-506.

23. Visscher, M.; Davis, J.; Wickett, R. E ect of topical treatments on irritant hand dermatitis in health care workers. Am. J. Infect. Control 2009, 37, e1-e842. [CrossRef]

24. Pittet, D. Compliance with hand disinfection and its impact on hospital-acquired infections. J. Hosp. Infect. 2001, 48, S40-S46. [CrossRef]

25. Winnefeld, M.; Richard, M.A.; Drancourt, M.; Grob, J.J. Skin tolerance and e ectiveness of two hand decontamination procedures in everyday hospital use. Br. J. Dermatol. 2000, $1 \overline{4} 3,546-550$. [CrossRef] [PubMed]

26. Greenaway, R.E.; Ormandy, K.; Fellows, C.; Hollowood, T. Impact of hand sanitizer format (gel/foam/liquid) and dose amount on its sensory properties and acceptability for improving hand hygiene compliance. J. Hosp. Infect. 2018, 100, 195-201. [CrossRef]

27. Food and Drug Administration; HHS. Safety and E_ectiveness of Health Care Antiseptics; Topical Antimicrobial Drug Products for Over-the-Counter Human Use. Final Rule. Available online: https: //www.fda.gov/media/109956/download (accessed on 8 May 2020).

28. Compounding Expert Committee. Compounding Alcohol-Based Hand Sanitizer during COVID-19 Pandemic. Available online: https://www.usp.org/sites/default/files/usp/document/about/public-policy/uspcovid19- handrub.pdf (accessed on 8 May 2020).

29. Song, X.; Vossebein, L.; Zille, A. E cacy of disinfectant-impregnated wipes used for surface disinfection in hospitals: A review. Antimicrob. Resist. Infect. Control 2019, 8, 139. [CrossRef] [PubMed]

30. Centers for Disease Control and Prevention. Hand Hygiene in Healthcare Settings; Centers for Disease Control and Prevention: Atlanta, GA, USA, 2019.

31. Blaney, D.D.; Daly, E.R.; Kirkland, K.B.; Tongren, J.E.; Kelso, P.T.; Talbot, E.A. Use of alcohol-based hand sanitizers as a risk factor for norovirus outbreaks in long-term care facilities in northern New England: December 2006 to March 2007. Am. J. Infect. Control 2011, 39, 296-301. [CrossRef] [PubMed] Int. J. Environ. Res. Public Health 2020, 17, 332615 of 17 
32. Oughton, M.T.; Loo, V.G.; Dendukuri, N.; Fenn, S.; Libman, M.D. Hand Hygiene with Soap and Water Is Superior to Alcohol Rub and Antiseptic Wipes for Removal of Clostridium di_cile. Infect. Control Hosp. Epidemiol. 2009, 30, 939-944. [CrossRef]

33. Kampf, G.; Marschall, S.; Eggerstedt, S.; Ostermeyer, C. E_cacy of ethanol-based hand foams using clinically relevant amounts: A cross-over controlled study among healthy volunteers. BMC Infect. Dis. 2010, 10, 78. [CrossRef]

34. Stebbins, S.; Cummings, D.A.T.; Stark, J.H.; Vukotich, C.; Mitruka, K.; Thompson,W.; Rinaldo, C.; Roth, L.; Wagner, M.; Wisniewski, S.R.; et al. Reduction in the incidence of influenza A but not influenza B associated with use of hand sanitizer and cough hygiene in schools: A randomized controlled trial. Pediatr. Infect. Dis. J. 2011, 30, 921-926. [CrossRef]

35. Pinhas, A.R. A kinetic study using evaporation of di_erent types of hand-rub sanitizers. J. Chem. Educ. 2010, 87, 950-951. [CrossRef]

36. Coronado, G.D.; Holte, S.E.; Vigoren, E.M.; Gri th, W.C.; Barr, D.B.; Faustman, E.M.; Thompson, B. Do workplace and home protective practices protect farm workers? findings from the "For Healthy Kids" study. J. Occup. Environ. Med. 2012, 54, 1163-1169. [CrossRef]

37. World Health Organisation. WHO Guidelines on Hand Hygiene in Health Care: First Global Patient Safety Challenge: Clean Care Is Safer Care; World Health Organisation: Geneva, Switzerland, 2009.

38. Centers for Disease Control and Prevention. Chemical Disinfectants - Guideline for Disinfection and Sterilization in Healthcare Facilities; Centers for Disease Control and Prevention: Atlanta, GA, USA, 2016.

39. World Health Organization. Guide To Local Production: Who-Recommended Handrub Formulations; World Health Organisation: Geneva, Switzerland, 2015.

40. Ison, S.; Beattie, M. Disinfection, sterilization and preservation (5th ed). Aust. Infect. Control 2002, 7, 74. [CrossRef]

41. Fehr, A.R.; Perlman, S. Coronaviruses: An overview of their replication and pathogenesis. In Coronaviruses: Methods and Protocols; Springer: New York, NY, USA, 2015; pp. 1-23.

42. Centers for Disease Control and Prevention. Guideline for Disinfection and Sterilization in Healthcare Facilities. $2008 . \quad$ Available online: https://www.cdc.gov/infectioncontrol/guidelines/disinfection/disinfectionmethods /chemical.html (accessed on 8 May 2020).

43. Teodorescu, M.; Bercea, M. Poly(vinylpyrrolidone)-A Versatile Polymer for Biomedical and Beyond Medical Applications. Polym. Plast. Technol. Eng. 2015, 54, 923-943. [CrossRef]

44. Dexter, F.; Parra, M.C.; Brown, J.R.; Loftus, R.W. Perioperative COVID-19 Defense: An Evidence-Based Approach for Optimization of Infection Control and Operating Room Management. Anesth. Analg. 2020. [CrossRef] [PubMed]

45. Jones, R.D.; Jampani, H.B.; Newman, J.L.; Lee, A.S. Triclosan: A review of e_ectiveness and safety in health care settings. Am. J. Infect. Control 2000, 28, 184-196. [CrossRef] [PubMed] Int. J. Environ. Res. Public Health 2020, 17, 332616 of 17

46. Fahimipour, A.K.; Ben Mamaar, S.; McFarland, A.G.; Blaustein, R.A.; Chen, J.; Glawe, A.J.; Kline, J.; Green, J.L.; Halden, R.U.; Van Den Wymelenberg, K.; et al. Antimicrobial Chemicals Associate with Microbial Function and Antibiotic Resistance Indoors. Am. Soc. Microbiol. 2018, 3, e00200-18. [CrossRef] [PubMed]

47. Honari, G.; Maibach, H. Skin Structure and Function. In Applied Dermatotoxicology; Elsevier: Amsterdam, The Netherlands, 2014; pp. 1-10.

48. Wickett, R.R.; Visscher, M.O. Structure and function of the epidermal barrier. Am. J. Infect. Control 2006, 34, S98-S110. [CrossRef]

49. Feingold, K.R. Lamellar bodies: The key to cutaneous barrier function. J. Investig. Dermatol. 2012, 132 , 1951-1953. [CrossRef] [PubMed]

50. Clayton, K.; Vallejo, A.F.; Davies, J.; Sirvent, S.; Polak, M.E. Langerhans cells-programmed by the epidermis. Front. Immunol. 2017, 8, 1676. [CrossRef]

51. Abraham, J.; Mathew, S. Merkel Cells: A Collective Review of Current Concepts. Int. J. Appl. Basic Med. Res. 2019, 9, 9-13.

52. Chiller, K.; Selkin, B.A.; Murakawa, G.J. Skin microflora and bacterial infections of the skin. J. Investig. Dermatol. Symp. Proc. 2001, 6, 170-174. [CrossRef]

53. Cogen, A.L.; Nizet, V.; Gallo, R.L. Skin microbiota: A source of disease or defence? Br. J. Dermatol. 2008, 158, 442-455. [CrossRef]

54. Grice, E.A.; Segre, J.A. The skin microbiome. Nat. Rev. Microbiol. 2011, 9, 244-253. [CrossRef]

55. Nash, A.A.; Dalziel, R.G.; Fitzgerald, J.R. Attachment to and Entry of Microorganisms into the Body. In Mims' Pathogenesis of Infectious Disease; Elsevier: Amsterdam, The Netherlands, 2015; pp. 9-49.

56. Wu, F.; Zhao, S.; Yu, B.; Chen, Y.-M.; Wang, W.; Song, Z.-G.; Hu, Y.; Tao, Z.-W.; Tian, J.-H.; Pei, Y.-Y.; 
et al. A new coronavirus associated with human respiratory disease in China. Nature 2020, 579, $265-269$. [CrossRef] [PubMed]

57. Zhou, P.; Yang, X.-L.; Wang, X.-G.; Hu, B.; Zhang, L.; Zhang, W.; Si, H.-R.; Zhu, Y.; Li, B.; Huang, C.-L.; et al. A pneumonia outbreak associated with a new coronavirus of probable bat origin. Nature 2020, 579, 270-273. [CrossRef] [PubMed]

58. Cascella, M.; Rajnik, M.; Cuomo, A.; Dulebohn, S.C.; Di Napoli, R. Features, Evaluation and Treatment Coronavirus (COVID-19); StatPearls Publishing: St. Petersburg, FL, USA, 2020.

59. Goldsmith, C.S.; Tatti, K.M.; Ksiazek, T.G.; Rollin, P.E.; Comer, J.A.; Lee, W.W.; Rota, P.A.; Bankamp, B.; Bellini,W.J.; Zaki, S.R. Ultrastructural Characterization of SARS Coronavirus. Emerg. Infect. Dis. 2004, 10, 320-326. [CrossRef] [PubMed]

60. Siddharta, A.; Pfaender, S.; Vielle, N.J.; Dijkman, R.; Friesland, M.; Becker, B.; Yang, J.; Engelmann, M.; Todt, D.;Windisch, M.P.; et al. Virucidal Activity ofWorld Health Organization-Recommended Formulations Against Enveloped Viruses, Including Zika, Ebola, and Emerging Coronaviruses. J. Infect. Dis. 2017, 215, 902-906. [CrossRef]

61. Kampf, G. E_cacy of ethanol against viruses in hand disinfection. J. Hosp. Infect. 2018, 98, 331-338. [CrossRef]

62. Rabenau, H.F.; Kampf, G.; Cinatl, J.; Doerr, H.W. E_cacy of various disinfectants against SARS coronavirus. J. Hosp. Infect. 2005, 61, 107-111. [CrossRef]

63. Ale, I.S.; Maibach, H.I. Irritant contact dermatitis. Rev. Environ. Health 2014, 29, 195-206. [CrossRef]

64. Misteli, H.; Weber, W.P.; Reck, S.; Rosenthal, R.; Zwahlen, M.; Fueglistaler, P.; Bolli, M.K.; Oertli, D.; Widmer, A.F.; Marti, W.R. Surgical glove perforation and the risk of surgical site infection. Arch. Surg. 2009, 144, 553-558. [CrossRef]

65. Lö_er, H.; Kampf, G.; Schmermund, D.; Maibach, H.I. How irritant is alcohol? Br. J. Dermatol. 2007, 157, 74-81. [CrossRef] Int. J. Environ. Res. Public Health 2020, 17, 332617 of 17

66. Graham, M.; Nixon, R.; Burrell, L.J.; Bolger, C.; Johnson, P.D.R.; Grayson, M.L. Low rates of cutaneous adverse reactions to alcohol-based hand hygiene solution during prolonged use in a large teaching hospital. Antimicrob. Agents Chemother. 2005, 49, 4404-4405. [CrossRef] [PubMed]

67. Angelova-Fischer, I.; Dapic, I.; Hoek, A.K.; Jakasa, I.; Fischer, T.W.; Zillikens, D.; Kezic, S. Skin barrier integrity and natural moisturising factor levels after cumulative dermal exposure to alkaline agents in atopic dermatitis. Acta Derm. Venereol. 2014, 94, 640-644. [CrossRef] [PubMed]

68. Cimiotti, J.P.; Marmur, E.S.; Nesin, M.; Hamlim-Cook, P.; Larson, E.L. Adverse reactions associated with an alcohol-based hand antiseptic among nurses in a neonatal intensive care unit. Am. J. Infect. Control 2003, 31, 43-48. [CrossRef]

69. Guin, J.D.; Goodman, J. Contact urticaria from benzyl alcohol presenting as intolerance to saline soaks. Contact Dermat. 2001, 45, 182-183. [CrossRef]

70. Bissett, L. Skin care: An essential component of hand hygiene and infection control. Br. J. Nurs. 2007, 16, 976-981. [CrossRef] [PubMed]

71. Larson, E.L.; Aiello, A.E.; Bastyr, J.; Lyle, C.; Stahl, J.; Cronquist, A.; Lai, L.; Della-Latta, P. Assessment of two hand hygiene regimens for intensive care unit personnel. Crit. Care Med. 2001, 29, 944-951. [CrossRef] [PubMed]

72. Boyce, J.M.; Kelliher, S.; Vallande, N. Skin Irritation and Dryness Associated With Two Hand-Hygiene Regimens: Soap-and-Water Hand Washing Versus Hand Antisepsis With an Alcoholic Hand Gel. Infect. Control Hosp. Epidemiol. 2000, 21, 442-448. [CrossRef] [PubMed]

73. Kantor, R.; Silverberg, J.I. Environmental risk factors and their role in the management of atopic dermatitis. Expert Rev. Clin. Immunol. 2017, 13, 15-26. [CrossRef]

74. Quality Medical Care Section; Medical Development Division; Ministry of Health Malaysia. Policies and Procedures on Infection Control. 2009. Available online: https://www.moh.gov.my/moh/images/gallery 